\title{
Surveillance \& Society \\ Eyes of Glass: \\ Article Watching the Watchers in the Monitoring of Public Places in Curitiba, Brazil
}

\section{Rodrigo José Firmino}

Pontifícia Universidade Católica do Paraná, Curitiba, Brazil.rodrigo.firmino@pucpr.br

\section{Elisa Trevisan}

Pontifícia Universidade Católica do Paraná, Curitiba, Brazil.elisa trevisan@yahoo.com.br

\begin{abstract}
Surveillance cameras have become an integral part of the architecture of public and private spaces in large cities, like the eyes of the augmented city (Firmino and Duarte 2008). From the perspective of public security and with the supposed premise of reducing violence, the implementation of security systems and the installation of these "eyes" in critical places have emerged as options available to town planners. However, there are no reliable data confirming a direct relationship between video surveillance and increased security, only the discussion and debate that has been started in an attempt to justify the use of such surveillance. Furthermore, little is known, particularly in Brazil, about the monitoring strategies and procedures used by the professionals who operate a city's eyes. As cameras are electronic devices whose purpose is merely to record images, the people who control them play a fundamental role in determining how this recording of images influences the day-to-day existence of those being watched and the very way the public space that is 'under surveillance' is perceived. To understand monitoring from the perspective of those who carry it out (Kemple and Huey 2005), we propose to show analytically, based on the study of a unit for monitoring public spaces in the center of Curitiba, what the watcher's procedures and routines are. It is the analysis of the images and of how best to proceed as a result of these that serves as the basis for all the actions involved in the operation of the system. Our aim was to gain first-hand experience of the monitoring unit with the aid of techniques such as participant observation in order to better understand what happens behind the glass eyes of the contemporary city.
\end{abstract}

Keywords: surveillance, video surveillance, control centers, monitoring, public spaces.

\section{Introduction}

A recent, growing phenomenon in the urban scenario, surveillance cameras (or simply video surveillance) have become a common part of our daily lives. Installed in both public and private spaces, they represent, for citizens in general and town planners and security organizations in particular, a powerful tool in the fight against violence and crime. Video surveillance carries the stigma of being a panacea for urban problems such as violence, vandalism and run-down city centers.

As with countless other current technological artifacts (whether associated with surveillance or not), video surveillance is becoming ubiquitous and infiltrating our daily lives and spaces ever more surreptitiously and invasively. This increasingly intimate relationship between technological artifacts, especially information and communications technologies (ICTs), and the environment, most notably the urban environment, has been interpreted by many specialists studying the subject as a phenomenon known as 
augmented space and, by analogy, augmented city (Manovich 2002; Aurigi and Cindio 2008; Firmino 2008; Firmino; Duarte 2008) or in some cases simply as infiltrated city because of the invasive character the technologies acquire (Duarte 2004). This augmentation of space and our communicational abilities implies various changes in the urban space (as a phenomenon) and consequently in all our lives: changes in the way we see, perceive, feel, understand, experience, share, use and, lastly, conceive and construct urban space (whether public or private).

However, like all technological systems, cameras alone cannot carry out any action without preprogrammed intent by human beings. An awareness of this assignment of social responsibilities to the functionality of technological devices avoids approaches that are tendentiously laden with a technological determinism harmful to an understanding of culturally complex social realities. In other words, when we study video surveillance systems, for example, and when we attempt to understand what type of influence these systems exert on the urban environment, we must first of all accept that they are part of a complex network of social constructs inserted in a chain of diverse historical developments. The theory of the social construction of technologies (Bijker 1987; Aibar and Bijker 1997) provides us with an enlightening view of the relationship between society and technologies (the latter being at the same time a product of and the motor of the former). The power of cameras in video surveillance systems resides, in fact, in their power to extend the ability to see of those responsible for security by means of artifacts that merely record, digitize and transmit images without implicit meanings. These meanings are given to images in a process Smith (2004) calls 'the human element', which can be divided into three parts: observation, interpretation and response. Without this, Smith correctly argues - corroborating the theory of the social construction of technologies - that any surveillance system becomes completely futile.

Most writers seem almost to forget that, by and large, CCTV cameras are neither conscious, nor autonomous, and require, in order to be effective, constant monitoring and control by human beings in a work-like situation, so that the millions of images produced can be watched, interpreted and acted upon (Smith 2004: 377).

In Brazil, little is known about the profession of these operators. It is through the perception and interpretation of the images produced that what happens outside control rooms is determined, i.e., a sequence of actions that directly affects the person being watched. This work therefore seeks to follow in the footsteps of Gavin Smith in his ethnographic observational studies in control centers (Smith 2004; Smith 2007) and to apply the techniques of participant observation during short periods of immersion in the CIMEC (Curitiba Integrated Electronic Monitoring Center), which is responsible for monitoring surveillance cameras in public spaces in the city of Curitiba.

To describe this experience, this paper is divided into three sections, followed by a conclusion. The first briefly and succinctly introduces the vision framing our interpretation of the importance of the issue of surveillance, in particular video surveillance, for urban studies. The second section describes similarly briefly the aims of and methods used in the observation of the watchers. Finally, in the third section, which is of course longer, we describe and discuss the situations found "behind the glass eyes" of more than 40 cameras in public spaces in Curitiba in an analysis of the procedures and actions of the individuals responsible for what Smith called the human element in the control of video surveillance.

\section{Augmented city, watched space}

The widespread dissemination of ICTs - especially the more recent advances in mobile and wireless technologies - has been the subject of multidisciplinary efforts to reconceptualize the relationships between space, time and technology. Town planners and specialists studying town planning face a major challenge insofar as new notions of space and time question old paradigms, a process that in turn affects 
how ICTs are incorporated in governance, planning and public policy agendas. This "challenge to spatial paradigms" affects the whole chain of events related to the analysis and management of spatial, economic, political, social and cultural aspects of contemporary urban life and constitutes what is perhaps the greatest task when considering the relationships between cities and ICTs.

Contradictorily, however, ICTs and their material effects are extremely difficult to identify accurately, partly because they are invisible compared with traditional urban structures. Unlike transport and other types of infrastructure, ICTs are very often supported by underground or invisible fiber optic networks, microwave radio and satellite radio signals and go unnoticed, in contrast to large urban infrastructure. Duarte (2004) calls this phenomenon the "infiltrated city", where ever-smaller, more ubiquitous and more invasive technologies infiltrate themselves, taking over various aspects of our day-to-day lives in cities.

\section{Infiltrated technologies, augmented city}

The difficulties in specifying exactly the effects and infrastructure associated with ICTs make their relationship with cities a doubtful and uncertain phenomenon from a theoretical and empirical point of view. The phenomenon of quasi symbiosis between technologies in urban space has been given various names, including "the infiltrated city" (Duarte 2004), as previously mentioned, and "recombinant architecture" (Mitchell 1995). There are infiltrated technologies in the environments and spaces in which we live that are able to expand our ability to interact and communicate both among ourselves and with the medium surrounding us, what Duarte and Firmino (2009) prefer to call the augmented city, related to what Manovich (2002) calls augmented space.

This symbiotic phenomenon of technologies in urban space, of infiltrated technologies, hides some important aspects of the development of contemporary urban life that have been neglected to date by specialists studying town and regional planning. Among these, the issue of the control of space and information in cities (as well as the images of video surveillance systems) emerges as a key paradigm at a time when community life - affected by new patterns of individualized behavior in cities - and global geopolitics - marked by global anti-terrorism movements triggered by the United States — are being reformulated. ICTs in particular have led to the expansion and simultaneous questioning of the possibilities for control that are ever-present in life in society.

Several of these characteristics also increase our ability to communicate, interact and process/manipulate information, changing our relationship with space and thus establishing the notion of an augmented reality/city.

\section{Control, space, time and territory}

ICTs are considered the most pervasive and ubiquitous set of technologies ever. There is a tendency nowadays for everything to have a microchip built into it (from planes and computers through refrigerators with Internet access to the human body itself). Unlike Duarte and Mitchell, Mark Weiser (1991) prefers to call this symbiosis between traditional and electronic elements "ubiquitous computing". This choice of terminology turns out to be fundamental insofar as the term "ubiquitous computing" expresses the incredible invasiveness of ICTs and the power they have to "disappear" and combine with other elements to become infiltrated technologies.

For Cuff (2003), the concept of ubiquitous computing has serious implications for the way we perceive and interact with space. Using a comparison with Bentham's panopticon (expanded upon by Foucault) and George Orwell's "Big Brother", she asserts that contemporary urban space is part of a highly controlled environment, which she calls "the enacted environment". "Seeing without being seen" (panopticon) and the controlled society (Big Brother) represent ways of seeing that are constants in an enacted environment, as ICTs allow information to be organized and managed in such a way that, depending on the enacting of 
certain parameters, they can have a direct or indirect influence on the conception, construction, use, working and organization of urban space.

Cuff also relates the gradual increase in the use of ubiquitous computing devices to transformations in notions of civility, civil rights, privacy and public life, which are affected by the increased control and surveillance in urban space. This relationship can be seen in the events following the September 11 terrorist attacks, which included approval in the USA of what is known as the Patriot Act, curtailing various rights and limiting the freedom of expression of American citizens and visitors to that country.

Rosa Moura (2004) calls the urban manifestation of these increased possibilities for control and surveillance "the watched city" and compares it to the ideal(ized) and restricted universe of the Truman Show, the famous 1998 film by Peter Weir:

Eternal surveillance hovers over buildings, equipment and moving vehicles and is used not only for security but also for control. A range of information, from "geographic intelligence", which georeferences urban objects and personal indicators, to systems containing an individual's genetic sequence, will be available not only to security organizations but also to the labor and consumer market. The city is imprisoned, intermediated by the screen. Information and communication technologies bring the permanent present (without a collective memory), ubiquitousness and real time to the unreality of virtual space. The public space of interpersonal relationships gives way to privatized space mediated by machines (Moura 2004: 2).

According to Murakami Wood and Graham (2006), surveillance studies are part of a multidisciplinary field of social sciences yet fail to a large extent to address spatial questions. These same authors also assert that the subject has grown substantially in importance following the publication of works by Giddens (1985) and particularly Foucault, in Discipline and Punish (1977), which brings together a large number of works supporting his theories about the panopticon.

Boosted by ICTs, surveillance technologies are increasingly invisible and melted into the built space, and the material forms that sustain our current urban way of life (therefore, infiltrated technologies). Thus, we can say that surveillance has become an intrinsic part of the space, and as such, it tends to make visible the invisible and immaterial components of places and territories. In other words, to rationalize the many flows of people, places, objects and actions for the sake of surveillance, these technologies organize information, bits and bytes for specific purposes, unifying and giving visibility to what was spread and intangible. There can be no doubt that the possibilities for control and surveillance of individuals and collectivities represent a challenge in terms of understanding and analyzing some of these consequences. In the following sections we seek to understand in great detail how the relationship between one of these infiltrated technologies (video surveillance) - part of the augmented city - and the human element works in the social construction of technologies for the surveillance and control of urban space.

\section{Methods: Watching the watchers}

The city of Curitiba is the capital of one of the three states (State of Paraná) that define the South Region of Brazil. According to the last census $(2010)^{1}$, there are approximately 1.8 million people living in the city, and about 3.1 million in its metropolitan region. Curitiba is well known worldwide for its planning and public transportation experiences in the late 1960s, which have given the city the fame of the place where the first Bus Rapid Transit System (BRT) was ever introduced. Many other labels are given to this

1 Instituto Brasileiro de Geografia e Estatística (Brazilian Institute of Geography and Statistics), IBGE: http://www.censo2010.ibge.gov.br/resultados do censo2010.php 
city, many of which are related to its innovative approach to urban technology and sustainability, especially within global South countries.

The city center in Curitiba, more specifically the Rua XV de Novembro - one of the most important commercial streets in town, which is also known as Brazil's first pedestrinized street - and surrounding area (Figure 1), is equipped with 41 cameras (with plans to expand it very quickly) and a control center known as CIMEC (Curitiba Integrated Electronic Monitoring Center, located at Praça Osório, at the end of Rua XV de Novembro), where the surveillance camera operators in Curitiba work. CIMEC was conceived and implemented by the municipality, under the responsibility of the Municipal Secretary of Social Defense (SMDS from the Portuguese Secretaria Municipal de Defesa Social), created in 2003.

The facility was initially developed to monitor only the Rua XV de Novembro as part of its revitalization project, and was conceived to target small crimes such as pickpocketing and shoplifting (which were said to be a problem in the area). However, after the first phase of its implementation (with the installation of the first cameras in the Rua XV de Novembro and CIMEC's building itself), the monitoring plans were expanded to the surrounding areas (focusing on historic buildings and sites) and to public parks. All cameras installed in these areas are monitored by CIMEC, which was turned into the city's monitoring center (and not only downtown's center).

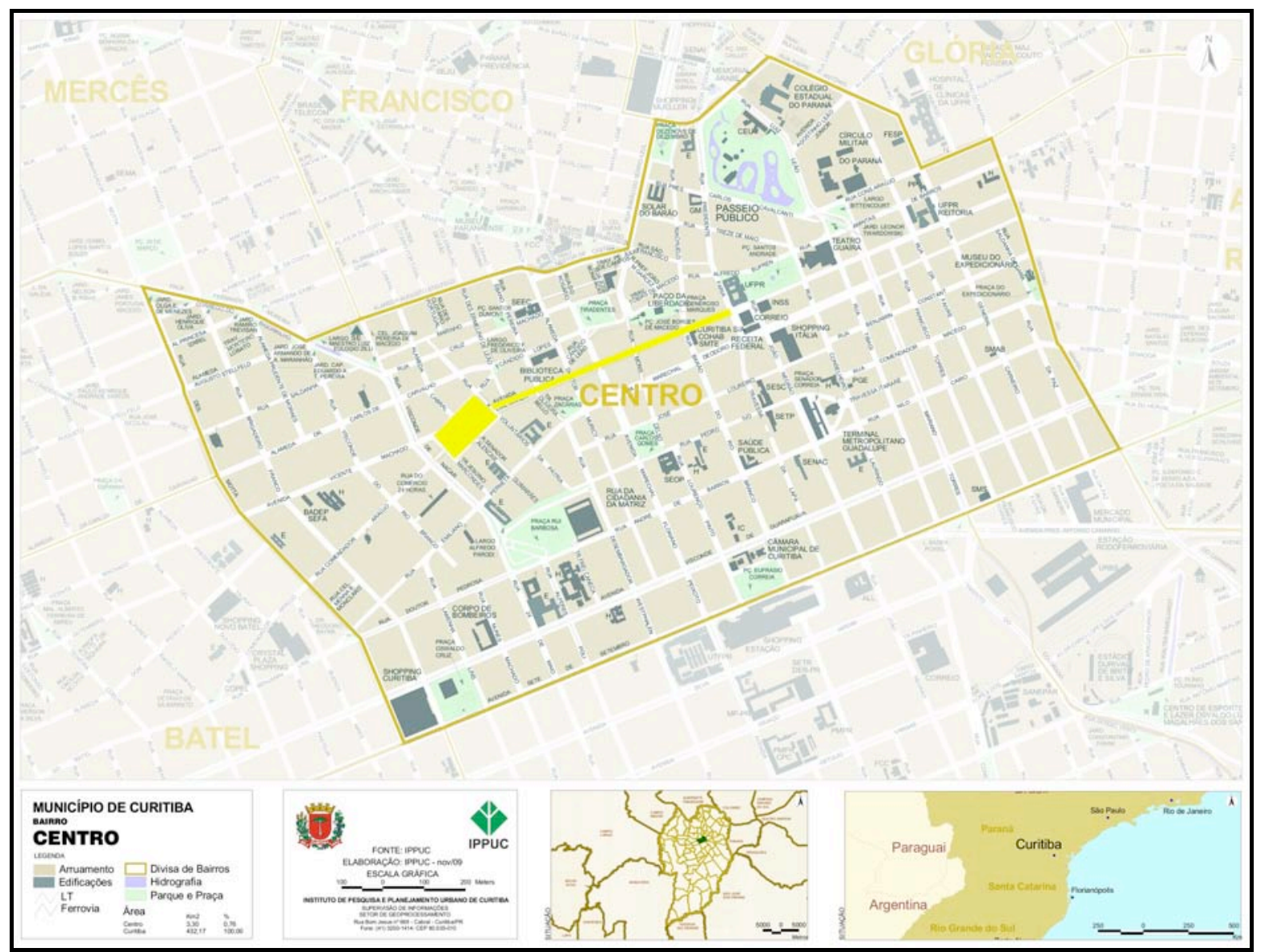

Figure 1: Curitiba city center; Rua XV de Novembro and Praça Osório highlighted in yellow. Source: IPPUC, $2011 .^{2}$

2 Instituto de Pesquisa e Planejamento Urbano de Curitiba (Curitiba Research and Urban Planning Institute), IPPUC: http://www.ippuc.org.br 
The center operates 24 hours a day, 7 days a week, throughout the year, and it operation is shared between other departments within the city as well as the municipal and state police forces. Six operators work there: a military policeman (state police force), a Diretran (Curitiba Department of Transport) employee, another from the SMU (Municipal Town Planning Department) and three municipal guards (one of whom is a supervisor).

All the research for this study was carried out during visits to the control center over a short period. The visits (always carried out by the same researcher) took place at different times of the day and night so that the busier and quieter periods could be identified. This strategy also allowed us to observe and talk with various operators, as well as to identify the changes in focus during the course of the day.

As previously mentioned, we used ethnographic techniques to understand the internal processes and attitudes involved in the operation of the cameras and normally hidden in the operators' actions and formal responsibilities. These techniques involved our acquiring an understanding of and interpreting the routine and behavior of the operators by immersing ourselves in the work of the CIMEC. One of the techniques used was participant observation, i.e., investigation characterized by interaction with the people who are the subject of the study and learning by taking part in and sharing activities in an attempt to ensure that observer and observed are on the same side. Participant observation can be divided into three types: peripheral, active and complete participant observation. This research falls into the first category, as the observer merely participates sufficiently to be admitted as a "member" without carrying out a member's activities.

According to Genzuk (1993), the three methodological principles that characterize ethnography are naturalism (understanding human behavior in settings that exist independently of the research process); understanding (the ability of the observer to understand situations from the point of view of those being observed); and discovery (an approach to a phenomenon that is free from any preconceived ideas).

The choice of this methodology, as previously mentioned, is justified by the experience of Smith (2004; 2007), who carried out various ethnographic studies of people involved in the operation of cameras and control centers in other countries. One of these studies discusses the observations of an outsider in the monitoring environment, the difficulties faced by the observers, the efficiency of the system and the target groups.

Thus, for this study, we organized a schedule of four visits (of three to four hours) for each period of the day (morning, afternoon, evening), arranging the visits to different weekdays, to allow covering the beginning, the middle and the end of the week. Apart from these, there was also the very first visit when the supervisor on duty exaplained the whole place and procedures, in a sort of guided tour through the center. This arrangement allowed us to vary the techniques used during the visits, distinguishing the procedures in the field in two principal types: (a) in the first visit (for each period), we always looked for as much interaction and explanations as possible, in order to acquire a first approach to the operators and their actions, as well as gain their confidence; (b) and in the three following visits, we assumed the position of mere observers, paying attention to every detail and taking notes of relevant information, reducing interactions to a minimum.

Starting from the principle that cameras do not work by themselves but depend on someone to give meaning to the images they capture, the aim of this study was to observe this task as it was carried out, to learn about the daily routine, the shifts, training and the interaction between the operators and the teams working in the field, as well as the psychological aspects of the profession. We took part in the activities of the center in 13 separate visits, during which many of the questions we had were answered in informal conversations with the CIMEC team. In the following sections we describe the process as we perceived it and its implications for the system of video surveillance of public spaces in Curitiba. 


\section{Behind the eyes of glass}

Curitiba was one of the pioneering cities in the implementation of a camera surveillance system to monitor part of the city center, the aim of which was, as stated by the City Council, to reduce urban crime rates and create a greater sense of security in the city center. The use of a rhetorical mentality to justify surveillance systems in support of public security in city centers is in complete accordance with interventions in European city centers during the 90 s by what are known as the Town Centre Management Groups. One of the main guidelines these groups (which are very common in the United Kingdom) give to city councils revitalizing city centers recommends that video surveillance systems should be installed (Bannister, Fyfe and Kearns 1998).

\section{The system and how it operates}

In March 2008, Curitiba town council inaugurated the CIMEC with the installation of 22 cameras (in addition to 14 analog cameras already in place). These are connected over a fiber optic network and operate 24 hours a day. In the course of the same year a further five cameras were installed. The system is operated by municipal guards, military policemen and DIRETRAN and SMU staff who are officially tasked with catching scenes of crimes such as theft, robbery, disorderly behavior, graffiti, drug dealing and the possession of drugs, as well as traffic control. In the central district, there is now cameras monitoring in Rua Marechal Deodoro da Fonseca, Rua Marechal Floriano, Rua André de Barros, Rua Riachuelo, Rua Saldanha Marinho and Avenida Manoel Ribas as well as in Rua XV de Novembro. Because some cameras are installed at the junctions of two streets, the surveillance also extends to stretches of Rua João Negrão, Rua Monsenhor Celso, Rua Barão do Rio Branco, Rua Conselheiro Laurindo, Alameda Doutor Muricy, Rua Voluntários da Pátria and Rua Mariano Torres. For this study, what is important beyond the names of the streets affected by the gaze of the cameras, is the fact (as mentioned above) that all these streets are the main streets surrounding the area highlighted on Figure 1 (Rua XV de Novembro and Praça Osório), and that, together, they form the principal connections between downtown and surrounding neighborhoods, as well as define the areas of main historical interest at the core of the city.

The CIMEC is equipped with six computer workstations and four LCD televisions, and the images are stored on a hard drive for 30 days, from where they are sent to another hard drive to be filed in order and stored. If necessary, images of interest can be recorded on a DVD; however, the only workstation with this facility is the supervisor's. This is the only way that images can leave the CIMEC. The teams trained to carry out the monitoring consist of municipal guards, military policemen and a member of the SMU whose task is to check for illegal trading.

It is interesting to note that the CIMEC itself is equipped with an internal camera that monitors and controls the work done by the agents operating the cameras in the streets. This control is carried out by the office of the Secretary for Social Defense. The camera is positioned so that the whole room falls within its gaze, and a second one was to be installed in the opposite corner to film the rear of the benches during the period of our visits. This was the subject of many comments during the week, as the installation had been postponed several times for technical reasons. Talking about it, several operators made interesting comments, such as "It's Big Brother" (male, Operator 1) or "This is an invasion of our privacy" (male, Operator 2). Others even joked (male, Operator 3): "Let's stick a photo in front of it to make it look as though we're working". The purpose of the cameras was to prevent operators sleeping or doing things that were incompatible with their job. In the supervisor's opinion, their presence puts pressure on the people working there.

To our knowledge, none of the studies similar to this one (including those by Gavin Smith) refer to such a strategy for controlling monitoring, let alone a strategy in which this is done by an executive in the city council. Unfortunately we do not have any other information about how this control is carried out, but intend to investigate this further as a follow-up to this study. However, there can be little doubt that this 
self-monitoring is in line with the findings of previous studies (particularly those by Gavin Smith) showing the difficulties operators have concentrating throughout their whole shift because of the tedious nature of the activity and the working environment. It also seems to be the case in which officers, supervisors and, especially in this case, the secretary himself, do not rely on the routine of the control center to mark the efficiency of the system, perhaps discrediting the ability of humans to work during long shifts in the monitoring of public spaces through video screens.

As part of the strategy for the visits (as mentioned before), the aim for the first day was, first of all, to "find out" where the CIMEC was and to meet the center supervisor in a guided demonstration, during which we had our first impressions of how control is viewed by the employees who have to put it into practice. We had to find out where the CIMEC was located, and a particular feature of the main office was that there was nothing to identify it. It should be noted that this was the result of an attempt by the coordinators of the center themselves to avoid constant visits by passersby and shopkeepers trying to lodge complaints because they had confused the CIMEC with a regular police station.

The center is surrounded by a fence and only people who have authorization can gain access. It is housed in a small building, which helps achieve the supervisors' aim of "disguising" it. There is a small hall at the entrance where the supervisor works. Beside his table, a large window gives a view of the monitoring room. This has two benches with 3 computers on each, lockers where the operators leave their belongings and four large televisions where the images from the cameras can be seen. Although there are three high windows, the light is mainly artificial.

The operators work a variety of rosters. The municipal guards work 12 hour shifts, made up of 6 hours in the CIMEC and 6 hours in the streets. The policemen work a roster consisting of a 6 hour shift one day; an 8 hour shift the next day; a 10 hour shift the following day; and then a day off. The DIRETRAN and SMU operators stay in the control room during the day and also work shifts in other locations. Both the guards and the police officers were all men, whereas the DIRETRAN and SMU staff were women. Although this mixture of sexes contrasts with the findings reported in other studies of control centers as male environments, we have not investigated these differences any further in order to see if they influence the way the system operates or the visions are negotiated.

At first sight, the operating system (Vidos) is simple. The operators choose which cameras they want to monitor and with a simple click of the mouse (or with the help of joysticks) can bring the images up on the screen. They can also choose between viewing four or nine cameras on a screen. The preferred number of cameras is four, as the more cameras on the screen, the more difficult it is to notice a situation that deviates from what is considered normal. By zooming in it is possible to see quite clearly what people are carrying in their hands and, occasionally, to see inside some shops. This was a consideration when cameras were installed in the Largo da Ordem (a well known historic site in Curitiba), where residents asked for the cameras to be installed further from the ground in order to protect their privacy.

The program allows a camera tour to be configured, i.e., an automatic mode in which the path is followed by the camera and points of interest are defined (bank branches and bus "tube" stations, which receive more attention). The camera stops at these locations for a specified dwell time and zooms in automatically. If the operator wants to see something, he can switch to manual mode. For all the cameras, a daytime tour (tour A) and nighttime tour (tour B) are defined by the supervisor to take into account the differences between the events during the day and during the night.

It is interesting to note that in general the population does not notice the cameras even though there are signs all along the Rua XV de Novembro. As well as filming the public, the cameras also film the activities of the police and guards in the streets. Cases of police violence and overreaction recorded by the 
cameras are used later in training courses to show police officers how to behave correctly. The cameras are also used to see if there are police near the scenes of any incidents.

\section{The daily routine in the monitoring room}

We now provide a detailed description of the monitoring environment at different times of the day based on our experiences during our immersion.

In the morning the center is relatively busy as the cleaning team is present and the operators go in and out of the monitoring room to have a coffee. The room is never empty but all six operators are rarely all present at the same time because at this time of the day they are working different shifts.

The operators are required to use the system to record the time they start and finish work. Another important function in the system is "Changes and Events", where incidents (events) and changes in the room are recorded, such as when a faulty computer is taken away for repair or when a technical team arrives.

New incidents are recorded every day. Special cases (spaces and/or buildings of interest) receive particular attention, an example being the Paço Municipal. ${ }^{3}$ On the days when we were visiting, the building, which was being refurbished, was the sole focus of the camera in this region. The reason for this was that the hoarding protecting the building from graffiti artists had been removed. Another example was the Praça Santos Andrade, a known gathering place for demonstrations. Coincidentally, at the time of our visits there was a security guards' strike and the guards were demonstrating in the square. The orders for this type of focused monitoring come from the Department of Social Defense, as the CIMEC reports to this government department. One of the reasons the square became a target of constant monitoring was that it is the natural stage for one of the commonest types of deviants: demonstrators. This makes it slightly different from the previous example, in which the space is monitored because it is itself a potential target for the actions of deviants.

During the day the most common incidents are the presence of street traders in prohibited areas and parking offenses. These activities are monitored by the operators from the appropriate department, in this case the SMU and DIRETRAN, respectively.

As pointed out in earlier works by Gavin Smith, the amount of attention paid by the operators and the routine they follow soon change. This is partly because of the monotonous nature of the work, partly because of the working conditions and partly because of the limitations inherent to a person's ability to concentrate (a person will rarely be able to pay complete attention to images on a screen and concentrate fully on them in shifts of 8,10 and 12 hours). Thus, as most of the time there are no serious incidents, the operators pay attention to normal things, such as a woman tripping, the path taken by the striking security guards or the route followed by gypsies going to their positions. In one specific case, the SMU operator, when she was monitoring legal street traders, pointed the camera to the trader's products and exclaimed: "I don't even need to go to the market to find out the price of strawberries!" (female, Operator 4). On another occasion she read the headlines in the newspaper vendor's stand.

A further example that illustrates perfectly the type of comments operators make while they are monitoring and the type of games they play that indirectly help them to break up the monotony without realizing it occurred when a gypsy reading a man's hand was being observed. It led to comments like:

She's talking about his wife. When he gets home she's going to get an earful (male, Operator 1); Even men are falling for her spiel (male, Operator 2); She must make a

\footnotetext{
${ }^{3}$ Paço Municipal: the former Town Hall, completed in 1916 and now a listed building.
} 
fortune (male, Operator 2); Look, look: ten bucks, I'm going to change job (male, Operator 1).

The operators even go so far as to simulate conversations between the two people and joke about whether anyone knows how to lip-read. When he was talking about his work to other policemen who did not know the center, one operator (male, Operator 2) even made the following comment: "You can even take photos of all the women in Rua VX de Novembro. I'll show you the album” (male, Operator 2).

The climate influences the activities in the monitoring center; at lunchtime, for example, there are more street traders, but because on this particular day it was raining nothing irregular was observed. Not even the peddling of umbrellas.

One afternoon, while the security guards' demonstration in the Praça Santos Andrade was being monitored, the policeman working on the shift received a call from an acquaintance who was taking part in the demonstration. He turned the camera and tried to find him, and when he did, described the camera to the acquaintance, who looked at the camera and laughed. The policeman told him that he would take a photo and send it to him later. We were told by the same policeman that this was one of the things the program can be used to do, i.e., to take photos of suspects or of criminals who are known to the police, which are then put in a folder that serves as a sort of database.

Here we can notice an interesting reaction from the operators, which is very common among all of them. They can be very ironic about their daily routine and usually show no embarrassment about making jokes or sensitive comments about any situation. However, whenever asked about their responsibilities and the importance of surveillance systems, they praise the technology enthusiastically and clearly demonstrate pride in their roles as operators of such an 'innovative' and 'useful' tool for the city. So, what is observed in practice during their routine is different to what is shown in their discourses.

The policemen and agents working in the CIMEC are also under great pressure to come up with answers and solutions to everyday problems of urban violence and disorder, which might explains the divergent behaviors described above. According to what the operators told us, their colleagues who do not work in the CIMEC think their job gives them the chance to sleep during shifts when there is nothing important happening. Reflecting Smith's findings once again, the pressure for answers (which in the case of Curitiba is even greater as a result of the self-monitoring) and the lack of recognition of the importance of the operators' work and efforts also help to create a somewhat rebellious attitude among the operators that is reflected in games and comments, casting doubt on just how effective surveillance systems are in reducing crime and creating a feeling of security in public places.

Technical failures were a regular part of the daily routine. During our visits, two computers broke down. When this happens, the operators record the fault details and fault number on the system, and the ICI (Instituto Curitiba de Informática, or Curitiba Informatics Institute) technicians are called out. The ICI is also responsible for minor repairs to the cameras. In cases involving more serious technical problems with the cameras, these are sent to the manufacturer for repair and are not replaced while they are away.

Internal day-to-day operations are also quite affected by physical events that interfere with the external systems, such as images being blocked by natural or artificial elements (trees, lampposts, advertising displays etc.). The operators were clearly quite bothered by these problems and mentioned how important the partnership CIMEC has with other city council departments is, an example being the partnership with the Department of the Environment to prune trees that interfere with the quality and coverage of the images. The positioning of the surveillance equipment is decided by the person in charge of the Department of Community Defense with advice from the ICI. The positioning of each camera is 
determined primarily according to the need, but also takes into account details such as cable route, the best location and any items blocking the camera's field of vision.

Because the system consists of many cameras, it is not easy to follow what happens in all of them, and the equipment is therefore usually left in automatic mode. Sometimes the operators move the cameras and take them out of automatic mode but seem to forget to put them back into this mode so they can operate automatically. When this happens, the cameras show images of the sidewalk, of cables, of the street, of people's feet as they walk and of other things that are not of any direct relevance to the monitoring. During the day, the focus varies between ordinary scenes such as a girl on the grass, a snack bar, commercial establishments and groups of people.

On the last day in the center the visit took place in the evening. When we arrived at around $6 \mathrm{pm}$ the door was locked; during the day it was usually left unlocked. The new camera had been installed that afternoon, but people's behavior in the room remained unchanged. Conversations about the previous day and about incidents and crimes the operators had witnessed were very common. In addition, small talk, such as when the DIRETRAN operator said she was afraid to ride a motorbike, was quite common. The operators who work on the night shifts are different from those who work during the day, as are the irregularities they observe.

At night the focus is on a number of bars that are quite lively. According to one of the night operators, on Monday nights one of the bars has a special offer that attracts a lot of people and is therefore the focus for the cameras. He also mentioned two cases that were missed by the cameras, one involving a couple that jumped from a building when the shifts were changing and nobody was monitoring, and another involving a murder "right underneath the cameras" (male, Operator 5), which were focused on some other activity at that time. He also recalled that when the system was first introduced there were more incidents, but that nowadays there are far fewer. In fact, it is well known that the incidents have migrated to areas where there is no surveillance. "When I started, they (the drug dealers) were all at the Banco do Brasil, now there's nobody" (male, Operator 5). For him it is easy up to $3 \mathrm{am}$, but after that everything gets a lot slower and it is difficult to stay awake. The worst time is when it rains because there are very few, if any, people in the streets.

Thus, once more, reality plays against operators' discourses. While it is known that most crimes migrated to other unwatched areas around downtown, and that this is one of the reasons crime rates went down in the 'protected' region, crimes new figures are loudly presented as the result of the system's implementation and no comments are made about other places. Aditionaly, lack of attention is one of the most mentioned characteristics of their work, especially when the streets are quiet.

It is the supervisor's duty to prepare a report with the statistics for the previous month. The system is used to keep a record of the details of incidents, the day the incident occurred and the person who was dealing with it. This provides information about which and how many incidents were dealt with by the Municipal Guard (responsible for practically half the incidents), the Military Police, the SMU and DIRETRAN. During December, for example, out of a total of approximately 120 incidents, 50 were dealt with by the Municipal Guard, mostly involving the use of narcotics. The same type of crime was dealt with by the Military Police. For DIRETRAN the commonest type of offense involved illegal parking, and for the SMU, street trading.

After all these comments and descriptions, we find ourselves agreeing once again with some of the observations made in other studies (Norris, Moran and Armstrong 1998; Smith 2004; Smith 2007; Crary 1999) about the influence exerted on the observation and evaluation of images by factors such as certain prejudices and stereotypes formed by the camera operators, the so-called 'boredom' factor, subconscious acts of resistance to rules and protocols, and the twin opposing relationship of power and dependence 
between operators and systems. In this relationship, according to Smith (2004), although they acquire the power to decide what they watch and make decisions regarding the images and the way they are interpreted, the operators become slaves to the system, as they find themselves in a situation where there is extremely little flexibility regarding actions, rules of conduct and procedures and where they are isolated in a dark room, hidden from outside eyes and tied to the same images that give them power.

The pressure on the operatives to capture any crime on video and react is constant and great. There is little scope for autonomy, spontaneity or diversity in their work; they simply come in and are paid minimally to watch habitual televisual images for hours on end. Hence, their job is frequently the epitome and quintessence of routine, in that it is standardized, mundane and predictable (Smith 2004: 391).

\section{Conclusion}

The effectiveness of a video surveillance system does indeed appear to depend on the behavior of the operators; however, and especially because of this, it is clear that the system is not perfect. As the cameras move around, they can leave behind images that may be important. The role of the operator is crucial in this type of system, as only his human character can give meaning to the millions of recorded scenes. Sensitivity, the ability to discern, training and a great deal of attention are needed to distinguish ordinary urban scenes from potential disturbances to what the public authorities consider normal attitudes. This human element is what makes the difference in the sociological interpretation of technological systems and their relationship with society when socio-constructivist and historical approaches are used.

This notion is both a fundamental and elementary one in the study of the influence of technology on the urban phenomenon. It is here, we would venture to say, that this study has a contribution to make, insofar as, together with other studies, it sheds light on the murky ground of the procedures and attitudes of the people known as the observers, without whom video surveillance systems are no more than technologies that do not work and serve no purpose. The study of these operations of observation, interpretation and reaction, as well of the operators, helps in the understanding of crucial aspects of the complex working of the surveillance and social control of groups and city spaces, and thus also helps in the understanding of important aspects of what is known as the augmented city, of watched spaces. The studies about spatial augmentation and the social construction of information and communication technologies as well as urban-technology, define a broad theoretical framework to understand how surveillance practices play a role in the waves of widespread uses of technology in the constitution of contemporary urban spaces, and the way we perceive, experience, plan and manage places and territories in the city.

As already mentioned, the "boredom factor" (Smith 2004), together with other cultural and sociobehavioral influences, also appears to affect the observers in Curitiba. They are in a boring situation brought about by the need to spend hours on end watching images that contain little action. As described by Smith (2004), the operators appear to overcome the boredom factor by a "secondary adjustment", i.e., by watching images and scenes of normal situations, inventing stories, playing games and making informal comments, such as when they watched the scene with the gypsy. At night particularly, the boredom becomes worse as there are fewer people, both in the CIMEC and in the streets.

As well as varying according to each operator's function, the focus also varies according to the sociopsychological characteristics of each operator. Although no clear evidences were presented (or even collected) to corroborate the following arguments, we believe (merely by what we have observed) that men tend to become very enthusiastic about more violent incidents, while women tend to be moved. The younger operators find things amusing, while the older ones behave more seriously. Personal prejudices also interfere with analysis of the images. 
All these factors appear to reinforce what is gradually being discovered in control centers in a variety of cultural contexts in different countries (irrespective of how advanced or otherwise the surveillance society in which they are found is), namely, that the neutrality and efficiency of video surveillance systems are exposed by the social relationships that actually go to make them up and by the various ramifications of what is known as the human element for their operation. This observation, however obvious it may seem, can only be confirmed by further studies concerned, like this one, with the ethnography and microsociology of certain processes (such as video surveillance) assumed by authorities and some specialists studying the subject to be automatic, efficient and dependent on the technological devices used. Looking through the eyes of glass makes us understand the complexity and relativity of the various processes and factors that influence and make up the operation of these technological surveillance systems.

We have also seen that the daily routine of the operators and their actions to overcome the monotony in their work contrast with what they say about the system's effectiveness and their own responsibilities. On one hand they are very relaxed about admitting there are problems of concentration and focus (perhaps without fully realizing it), while on the other hand, they are also confident that the system and their work are important for the city, especially regarding the prevention of crime.

Finally, in the case of Curitiba, this twin opposing relationship of power and dependence between operators and systems is exacerbated by the presence of self-monitoring, where two cameras ensure surveillance of the control center and operators themselves. This raises a number of as yet unanswered questions: how are the observers observed, what exactly is the target of this self-surveillance and who (within the office of the Secretary for Social Defense) monitors the observers? Hence, what started as an academic study into the watching of the watchers ended up by discovering and pointing out the curious attitude of self-monitoring in the system for the video surveillance of public spaces in Curitiba. Our findings revealed that there is in fact an official watching of the watchers that constitutes a second level of eyes of glass and suggests that the superimposed functions of control and monitoring are divided between different levels in the system's operational and political chain of command.

\section{Acknowledgement}

We are grateful to CNPq (Conselho Nacional de Desenvolvimento Cientifico e Tecnológico, Brazil) and Fundação Araucária (Brazil) for supporting the research upon which this article is based. We also would like to express our gratitude to the anonymous reviewers for their insightful comments.

\section{References}

Aibar, E. and Bijker, W. 1997. Constructing a City: The Cerdà Plan for the Extension of Barcelona. Science, Technology, \& Human values. 22 (1): 3-30.

Aurigi, A. and Cindio, F. de, eds. 2008. Augmented Public Spaces. Aldershot: Ashgate.

Bannister, J.; Fyfe, N. and Kearns, A. 1998. Closed-circuit television and the city, In: Norris, C.; Moran, J. and Armstrong, G., eds. 1998. Surveillance, closed circuit television and social control, Aldershat: Ashgate.

Bijker, W. 1987. Of Bicycles, Bakelites, and Bulbs: Toward a Theory of Sociotechnical Change. Cambridge MA: MIT Press.

Crary, J. 1999. Suspensions of Perception: attention, spectacle, and modern culture. Cambridge: MIT Press.

Cuff, D. 2003. Immanent Domain: Pervasive Computing and the Public Realm. Journal of Architectural Education. 57 (1): $43-9$.

Duarte, F. 2004. La ciudad infiltrada. Café de las ciudades. 3 (23), Septiembre 2004.

Duarte, F. and Firmino, R. 2009. Infiltrated city, augmented space: information and communication technologies, and representations of contemporary spatialities. The Journal of Architecture, 14 (5): 545-565.

Firmino, R. 2008. Planning and Managing the Augmented City: ICT planning in medium-sized cities in São Paulo, Brazil. In: Aurigi, A. and Cindio, F. de. eds. 2008. Augmented Public Spaces. Aldershot: Ashgate.

Firmino, R. and Duarte, F. 2008. Cidade infiltrada, espaço ampliado: as tecnologias de informação e comunicação e as representações das especialidades contemporâneas. Arquitextos (São Paulo. Online). 96: 1-14.

Genzuk, M. 1993. A Synthesis of Ethnographic Research. Occasional Papers Series. Center for Multilingual, Multicultural Research. Center for Multilingual, Multicultural Research, Rossier School of Education. Los Angeles: University of Southern California.

Giddens, A. 1985. The Nation-State and Violence. Cambridge: Polity Press. 
Kemple, T. and Huey, L. 2005. Observing the observers: researching surveillance and counter-surveillance on 'skid row'. Surveillance \& Society. 3 (2-3): 139-57.

Manovich, L. 2002. The Poetics of Augmented Space. In: Everett, A. and Caldwell, J. eds. 2002. Digitextuality. London: Routledge.

Mitchell, W. 1995. City of Bits: Space, Place and the Infobahn. Cambridge MA: MIT Press.

Moura, R. 2004. A cidade vigiada. The Truman Show, de Peter Weir, 1998. Arquitextos (São Paulo. Online). 53: 1-9.

Murakami Wood, D. and Graham, S. 2006. Permeable Boundaries in the Software-sorted Society: Surveillance and the Differentiation of Mobility. In: Sheller, M. and Urry, J. eds. 2006. Mobile Technologies of the City. London: Routledge, 177-191.

Norris, C; Moran, J and Armstrong, G. eds. 1998. Surveillance, closed circuit television and social control. Aldershot: Ashgate.

Smith, G. 2007. Exploring relations between watchers and watched in control(led) systems: strategies and tactics. Surveillance \& Society. 4 (4): 281-313.

Smith, G. 2004. Behind the screens: examining constructions of deviance and informal practices among CCTV control room operators in the UK. Surveillance \& Society, 2 (2): 376 - 395.

Weiser, M. 1991. The Computer for the Twenty-First Century. Scientific American: 94-104, September 1991. 